\title{
Study on Atmospheric Corrosion Behavior of Q235 Galvanized steel in Substation
}

\author{
Yong $\mathrm{Li}^{1, \mathrm{a}}$, Yongliang $\mathrm{Ji}^{1, \mathrm{~b}}$, Gaolin $\mathrm{Wu}^{1, \mathrm{c}}$, Wenjing Yang ${ }^{2, \mathrm{~d}}$, Qihui Wang ${ }^{2, \mathrm{e}}$ and \\ Xueming $\mathrm{Li}^{2, \mathrm{f}}$ \\ ${ }^{1}$ State Grid Chongqing Electric Power Research Institute, Chongqing, China \\ ${ }^{2}$ College of Chemistry and Chemical Engineering, Chongqing University, Chongqing, China

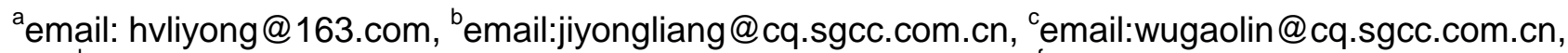 \\ demail: yangwj308@163.com, eemail:qihuiwang@cqu.edu.cn,email:xuemingli@cqu.edu.cn,
}

Keywords: Hot-dip galvanized steel, Atmospheric corrosion, Corrosion products, Electrochemical technique

Abstract. In this paper, the natural exposure corrosion behavior of Q235 galvanized steel in four different substation environment including urban population centers (A), rural settlements (B), industrial park (C) and chemical industrial park (D) are studied by potentiodynamic polarization and electrochemical impedance spectroscopy (EIS). In order to analyze the corrosion behavior comprehensively, the Q235 galvanized steel was insolated for $0 \sim 300$ days. In addition, the corrosion morphology and corrosion products of Q235 galvanized steel were investi gated by scanning electron microscopy (SEM) and energy dispersive spectrometer (EDS). Consequently, it is speculated that $\mathrm{Zn}(\mathrm{OH})_{2}, \mathrm{ZnCO}_{3}$ and $\mathrm{Zn}_{5}(\mathrm{CO})_{3}(\mathrm{OH})_{6}$ are the main corrosion products of galvanized steel. Moreover, it is found that the current density increase firstly and then reduce with the natural exposure extendi ng. In general, corrosion products adhering to the galvanized steel surface can promote the corrosion resistance effectively and prevent the sample from corrosion.

\section{Introduction}

The reliability requirement for power energy reliability is increasing with the rapid development of China's economy and society [1]. The safe and stable operation of power transmission and transformation equipment is closely related to people's daily lives. As an important part of power equipment, the corrosion life of power equipment determines its service life. Galvanized steel has been commonly used in the construction of power equipment due to the advantagment of good mechanical properties and low cost [2]. However, galvanized steel is affected by various environmental factors in atmospheric environment, resulting in larger corrosion damage. Therefore, it is important to study the atmospheric corrosion of galvanized steel and predict its corrosion life for the safe operation of power system in China [3-4].

Liu $\mathrm{Yu}$ wei et al. [5] studied the corrosion behavior of galvanized steel in simulated acid rain atmospheric environment by salt spray test. The results showed that the coating protection of galvanized steel increased with the temperature firstly and then decreased with the time. Liu Zhengchun et al. [6] reviewed the influencing factors of atmospheric corrosion of carbon steel, galvanized steel and copper. The three kinds of metal weight-loss laws were in line with the power function equation, and the atmospheric corrosion was influenced by the environment and pollutant species. The combination of natural exposure experiments and indoor corrosion experiment were more effective to predict law of atmospheric corrosion of metals and proposed appropriate protective measures. Liu Shuan et al. [7] studied three corrosion behaviors of galvanized steel in the atmosphere, sea water and reinforced concrete, and then discussed the influence of environmental factors such as $\mathrm{pH}$ value, temperature and chloride concentration on corrosion behavior of galvanized steel. 
In this paper, the corrosion behaviors of galvanized steel in four typical areas of substation were studied. The relationship between temperature, precipitation, $\mathrm{pH}$ of precipitation and corrosion behavior of galvanized steel was also investigated. It is great theoretical and practical value to study the law and mechanism of atmospheric corrosion of galvanized steel for predicting the service life of transmission tower poles and avoiding various electric accidents caused by corrosion.

\section{Experiment}

The surface of sample is hot dip galvanized layer, the substrate is Q235 steel and chemical composition of Q235 steel is C 0.14 wt \%, Si 0.19 wt\%, Mn 0.55 wt \%, P 0.028 wt \%, S 0.020 wt \%, Fe residue. Testing time is $0,60,120,180,240$ and $300 \mathrm{~d}$, respectively. The simulated acid rain is prepared according to the composition of local rain in recent years: $\mathrm{NaF} 0.29 \mathrm{mg} / \mathrm{L}, \mathrm{Na}_{2} \mathrm{SO}_{4} 0.36$ $\mathrm{mg} / \mathrm{L}, \mathrm{KNO}_{3} 1.52 \mathrm{mg} / \mathrm{L},(\mathrm{NH} 4)_{2} \mathrm{SO}_{4} 5.35 \mathrm{mg} / \mathrm{L}, \mathrm{MgSO}_{4} 0.97 \mathrm{mg} / \mathrm{L}, \mathrm{MgCl}_{2} 0.77 \mathrm{mg} / \mathrm{L}, \mathrm{NaNO}_{3} 0.51$ $\mathrm{mg} / \mathrm{L}, \mathrm{CaSO}_{4} 6.80 \mathrm{mg} / \mathrm{L}$ and the $\mathrm{pH}$ value of solution is adjusted by sulfuric acid to 6.0. Natural insolation point is located in 4 relatively typical regions of transformer substation. The selection of test points located in the densely populated city (A), rural settlements (B), Industrial Park (C) and Chemical Industrial Park (D), representing several typical atmospheric corrosion environments. During the experiment period, the test point temperature, precipitation and precipitation $\mathrm{pH}$ value are shown in Figure 1 Figure 3.

Different temperature will lead to different corrosion rate of metal. At different temperatures, the water vapor condensed on the metal surface is different, and the electrolyte solubility in metal surface water film is not the same. Generally, the rising of temperature will result in accelerated corrosion rates. During the experimental period, the variation of $\mathrm{A}, \mathrm{B}, \mathrm{C}$ and $\mathrm{D}$ substation temperature are shown in Figure 1. The test point temperature difference is small in the experimental period: average temperature of A substation $19.04{ }^{\circ} \mathrm{C}$, average temperature of $\mathrm{B}$ substation $19.48{ }^{\circ} \mathrm{C}$, average temperature of $\mathrm{C}$ substation $20.33{ }^{\circ} \mathrm{C}$, average temperature of $\mathrm{D}$ substation $20.32{ }^{\circ} \mathrm{C}$. It can be considered that the temperature has the same influence on the corrosion of galvanized steel during the experiment.

Precipitation will lead to the water film on the surface of metal, and corrosive gas dissolved in water film to form electrolyte solution, which will accelerate corrosion rate. In addition, precipitation will erode the corrosion products formed on the metal surface, promoting metal corrosion. However, the erosion of rainwater will reduce the concentration of electrolyte on the surface of metal, and decrease the corrosion rate of metal to a certain extent. Figure 2 displays the A, B, C, D substation precipitation during the experiment period: the A substation near the river, total precipitation in the experimental period is $3096.17 \mathrm{~mm}$, B substation precipitation is $1190.37 \mathrm{~mm}$, C substation precipitation is $1070.38 \mathrm{~mm}$ and $\mathrm{D}$ substation precipitation is $1303.20 \mathrm{~mm}$. A substation precipitation is much larger than the remaining 3 substations, and the difference of $\mathrm{B}, \mathrm{C}$ and $\mathrm{D}$ precipitation are small, the order of precipitation is $\mathrm{A}>\mathrm{D}>\mathrm{B}>\mathrm{C}$. 

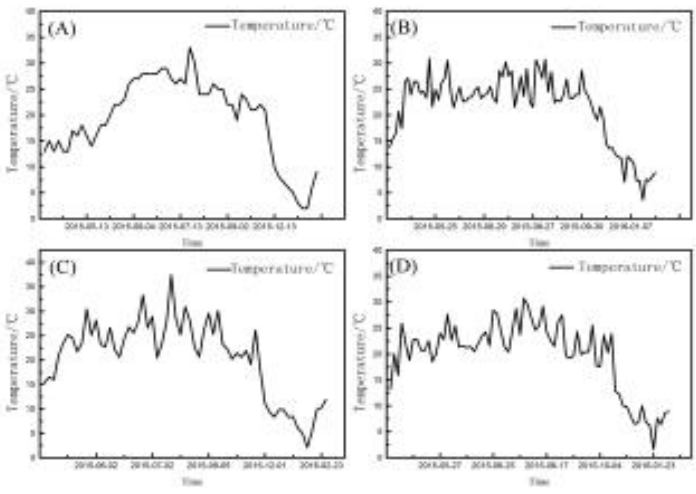

Fig. 1. Curves of temperature at substation of A、B、C、D with different experimental period
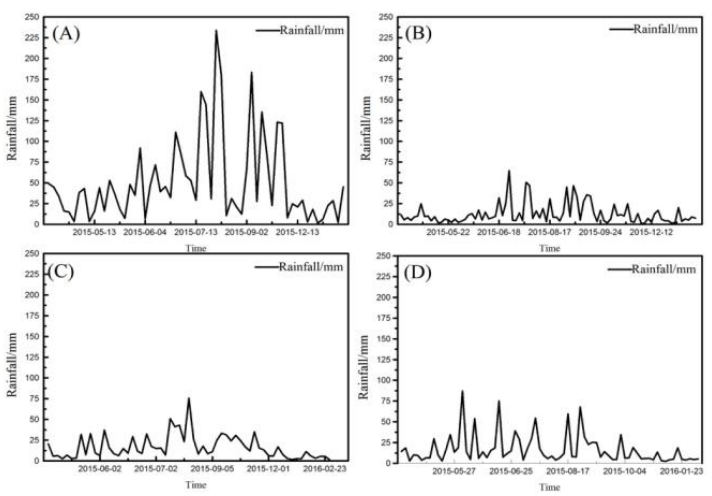

Fig. 2. Curves of rainfall at substation of A、B、C、D with different experimental period The emission of industrial production and automobile exhaust will lead to serious air pollution, such as sulfur dioxide and nitrogen oxides. When atmospheric relative humidity is large, acid gases such as sulfur dioxide and nitrogen oxide will dissolve in the rain, resulting in the formation of acid rain. The acid rain causes severe corrosion of metals exposed to atmospheric conditions. During the experiment period, the average precipitation $\mathrm{pH}$ value of the $\mathrm{A} 、 \mathrm{~B} 、 \mathrm{C} 、 \mathrm{D}$ substation is 6.91, 6.22, $5.79,5.92$, separately. The order of precipitation $\mathrm{pH}$ value is $\mathrm{A}>\mathrm{B}>\mathrm{D}>\mathrm{C}$.

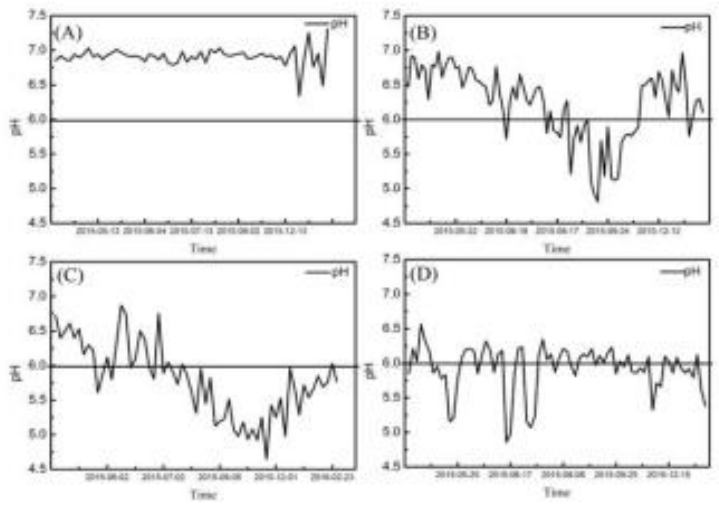

Fig. 3. The curves of $\mathrm{pH}$ values of precipitation at substation of $\mathrm{A} 、 \mathrm{~B} 、 \mathrm{C} 、 \mathrm{D}$ with different experimental period. 
Polarization curves are measured using PGSTAT 302 electrochemical workstation, scanning range of $-200 \sim+200 \mathrm{mV}$ (vs OCP), scanning speed of $10 \mathrm{mV} / \mathrm{s}$. Impedance sine wave potential amplitude is $10 \mathrm{mV}$, frequency range is $100 \mathrm{kHz} 0.01 \mathrm{~Hz}$. Zview software was used to analyze the impedance data and fit the equivalent circuit. Three electrode system was applied in the electrochemical test. Galvanized steel was used as a working electrode (WE), a platinum electrode and $\mathrm{Ag} / \mathrm{AgCl}$ electrode were used as the counter electrode (CE) and the reference electrode (RE), respectively. Figure 4 is the schematic illustration of a self-made electrolyzer with $4 \mathrm{~cm}$ diameter, vertical cylinder is embedded by PTFE coating, and the coating can prevent the electrolyte outflow after fitting.

\section{Results and Discussion}

\section{Polarization Curve Measurement}

The corrosion rate of galvanized steel in different substation is different. As the corrosion rate of metal can be expressed by corrosion current, the corrosion current of galvanized steel with different exposure time in different regions was obtained by extrapolation of dynamic potential polarization curve. Figure 5 shows the Tafel polarization curve of galvanized steel in 4 different areas with different exposure time (0 300 days).

The corrosion of galvanized steel in natural exposure experiment is mainly electrochemical corrosion, the corrosion rate can be expressed by the corrosion current density. The corrosion current density obtained by polarization curve fitting can reflect the corrosion rate of zinc coating. Figure 6 is corrosion current density of galvanized steel in different exposure periods.

As presented from Figure 6, with the increase of exposure time of galvanized steel, galvanized steel corrosion rate increased first and then decreased. It may result from the acid rain deposition in the early stage of experiment, which decreases the $\mathrm{pH}$ value of the electrolyte film of galvanized steel surface and the conductivity increases, leading to the increase of the corrosion current density of the initial galvanized steel and the corrosion rate. Subsequently, a layer of corrosion product is formed on the surface of galvanized steel, which reduce the corrosion current and lead the corrosion rate decreased gradually.

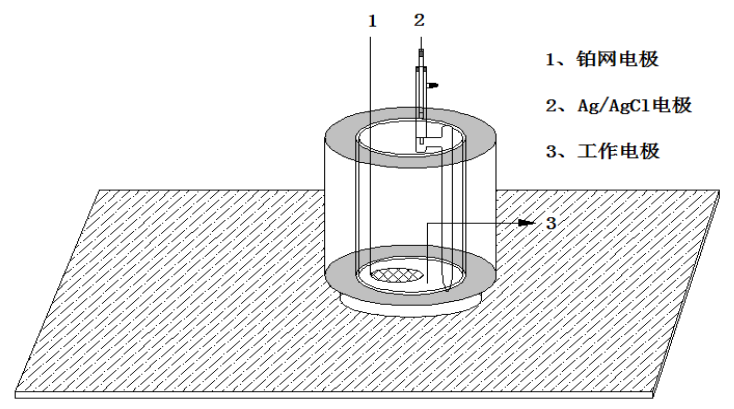

Fig. 4. Electrochemical testing system 

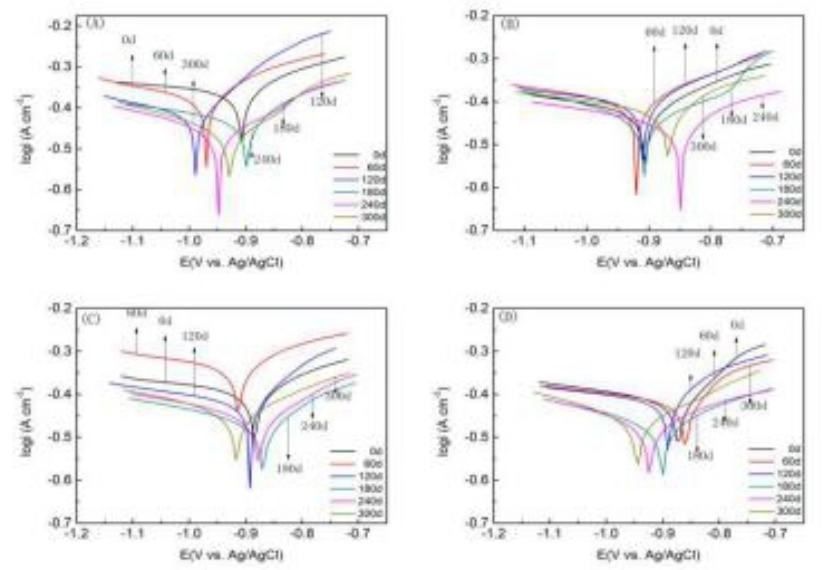

Fig. 5. Tafel curves of galvanized steel at substation of A、B、C、D with different experimental period

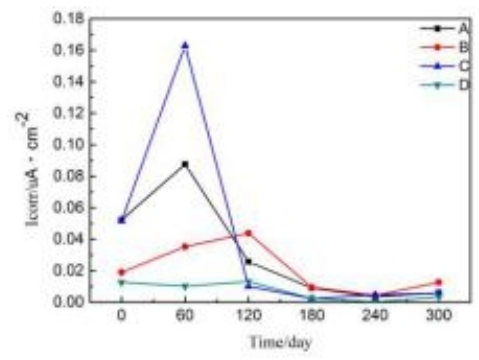

Fig. 6. Corrosion current density of galvanized steel at substation of A、B、C、D with different experimental period

The corrosive currents of galvanized steel in A, B, C and D have been shown in Figure 6, and the corrosive rate order is $\mathrm{C}>\mathrm{A}>\mathrm{B}>\mathrm{D}$, resulting from the difference of $\mathrm{A}, \mathrm{B}, \mathrm{C}, \mathrm{D}$ precipitation and $\mathrm{pH}$ values. Since the A place is close to Yangtze River, the precipitation of $\mathrm{A}$ is the highest in these four places. As a consequence, the corrosive rate of galvanized steel in the A place is the second highest due to the scour of rainwater. Moreover, the $\mathrm{pH}$ value order is $\mathrm{A}>\mathrm{B}>\mathrm{D}>\mathrm{C}$, resulting in the highest corrosive rate of galvanized steel in $\mathrm{C}$ place. The corrosive rate of galvanized steel in the $\mathrm{C}$ place is increased when under acid precipitation.

The corrosive rate of galvanized steel in A, B, C and D increased first and then decrease, which may be attributed to the formation of oxide film, which can protect the galvanized steel from the corrosion. The corrosive rate of galvanized steel decreased with the increase of oxide film thickness. The anticorrosion properties become to be stable when the galvanized steels were exposured in air atmosphere for 180 days.

\section{EIS measurement}

Figure 7 shows the variation of EIS with the increase of time, and the equivalent circuit diagram is displayed in Figure 8. Rs is the resistance of solution, Q is the double layer capacitance, Rct is the resistance of electrons transfer, which is usually used to evaluating the anticorrosion. The fitting parameters are listed in Table 1, and the variation of Rct as a function of time is shown in Figure 9. It is clear to be seen that Rct decreases first, and then increases with time going, indicating the increase of corrosive rate, and decrease of corrosive rate subsequently. After the exposure in air atmosphere, the corrosive products hinder the further corrosion of substrate. 

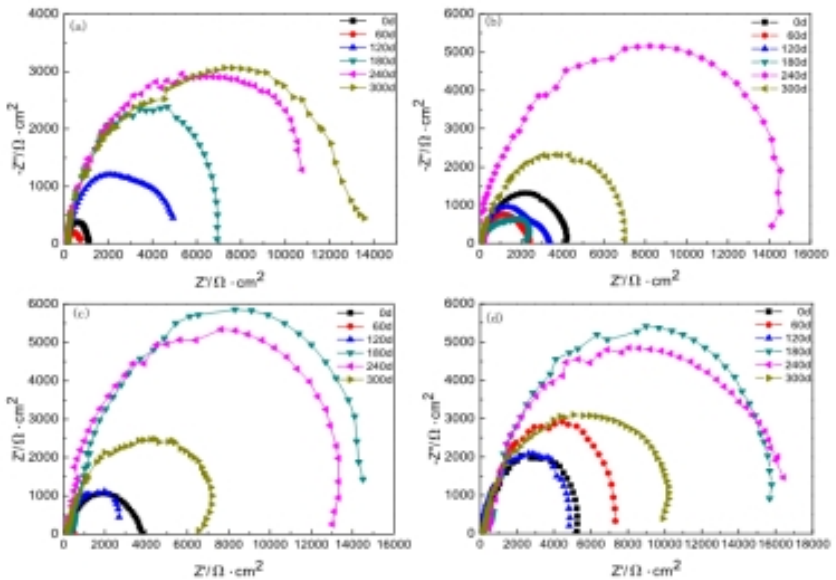

Fig. 7. EIS of galvanized steel at substation of A、B、C、D in the experimental period.

Table 1 EIS parameters of galvanized steel at substation of A、B、C、D in the experimental period.

\begin{tabular}{|c|c|c|c|c|c|}
\hline Test sites & $\begin{array}{c}\text { Corrosion } \\
\text { time/day }\end{array}$ & $\mathrm{Rs} / \Omega \cdot \mathrm{cm}^{-2}$ & $\mathrm{Q} / \mathrm{uF} \cdot \mathrm{cm}^{-2}$ & $\mathrm{n}$ & $\mathrm{R}_{\mathrm{ct}} / \Omega \cdot \mathrm{cm}^{-2}$ \\
\hline \multirow{5}{*}{ A } & 0 & 5.39 & 2.06 & 0.81412 & 83.52 \\
\hline & 60 & 12.48 & 2.36 & 0.7737 & 46.60 \\
\hline & 120 & 10.52 & 2.24 & 0.7266 & 350.72 \\
\hline & 180 & 10.84 & 1.24 & 0.79773 & 539.57 \\
\hline & 240 & 9.12 & 1.69 & 0.71721 & 796.42 \\
\hline \multirow{7}{*}{ B } & 300 & 8.88 & 2.60 & 0.67617 & 935.75 \\
\hline & 0 & 7.79 & 2.21 & 0.78444 & 286.78 \\
\hline & 60 & 12.84 & 1.51 & 0.84297 & 164.01 \\
\hline & 120 & 6.13 & 1.54 & 0.83388 & 233.04 \\
\hline & 180 & 10.96 & 7.57 & 0.67594 & 183.92 \\
\hline & 240 & 12.60 & 1.38 & 0.7787 & 1183.84 \\
\hline & 300 & 7.24 & 1.42 & 0.71197 & 578.26 \\
\hline \multirow{5}{*}{$\mathrm{C}$} & 0 & 12.38 & 3.20 & 0.73638 & 280.41 \\
\hline & 60 & 15.16 & 23.43 & 0.67629 & 25.10 \\
\hline & 120 & 13.31 & 1.28 & 0.87553 & 221.42 \\
\hline & 180 & 11.04 & 1.09 & 0.81147 & 1222.21 \\
\hline & 240 & 8.61 & 1.15 & 0.78825 & 1140.84 \\
\hline \multirow{7}{*}{ D } & 300 & 11.59 & 0.96 & 0.78299 & 565.92 \\
\hline & 0 & 13.39 & 1.12 & 0.84673 & 414.01 \\
\hline & 60 & 11.93 & 0.91 & 0.86692 & 568.47 \\
\hline & 120 & 8.14 & 1.02 & 0.83126 & 412.02 \\
\hline & 180 & 12.40 & 1.44 & 0.67861 & 1377.63 \\
\hline & 240 & 12.11 & 1.94 & 0.6229 & 1420.06 \\
\hline & 300 & 10.82 & 1.27 & 0.76195 & 770.14 \\
\hline
\end{tabular}

Fig. 8. Equivalent circuit diagram. 


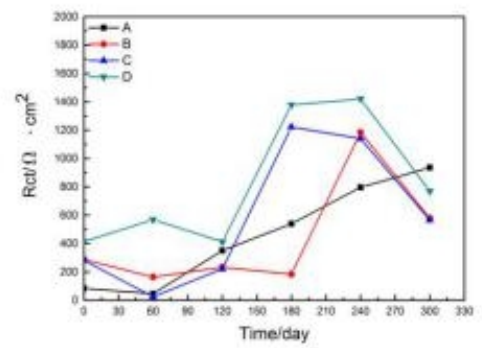

Fig. 9. Parameters Rct of galvanized steel at substation of A、B、C、D in the experimental Morphology and Components Analysis period.

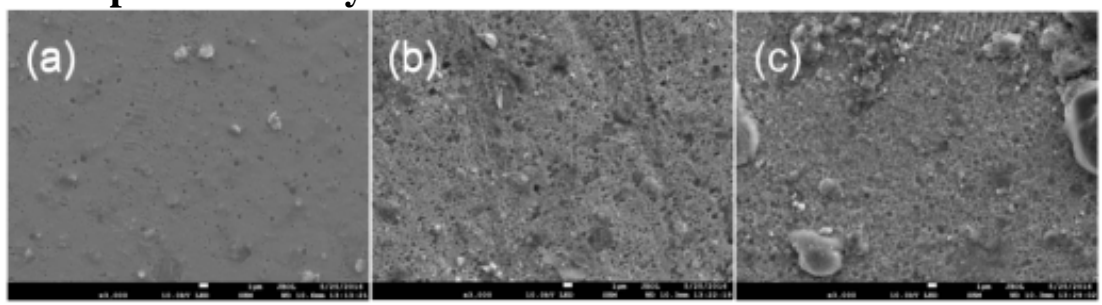

Fig. 10. Surface image of galvanized steel at substation of $\mathrm{C}$ in $0 \mathrm{~d}, 150 \mathrm{~d}, 300 \mathrm{~d}$.

The SEM images of galvanized steel in $\mathrm{C}$ transformer substation (industrial zone) are shown in Figure 10. It is clearly seen that the pore size of galvanized steel is around $0.2-0.6 \mu \mathrm{m}$ at early stage. The surface presents amounts of pores with small change in diameter after 150 day's exposure. When the corrosive time reaches to 300 days, the size and quantity of pores have no evident change, which may be attributed to the protect of corrosive products.

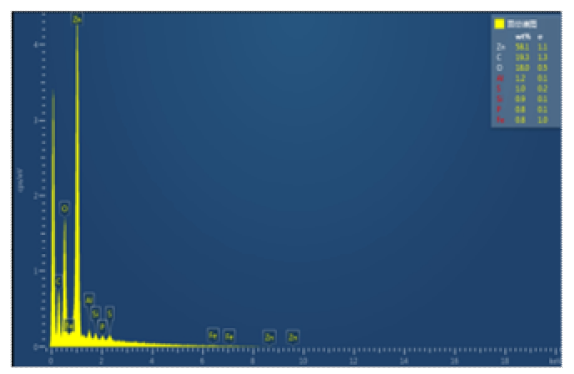

Fig. 11 EDS of galvanized steel at $C$ substation in $300 \mathrm{~d}$

Figure 11 presents the EDS result of galvanized steel in the $\mathrm{C}$ transformer substation. As shown in Figure 11, the main elements are $\mathrm{Zn}, \mathrm{C}$ and $\mathrm{O}$. Based on previous studies [8-10], the corrosive mechanism is proposed for galvanized steel under different air atmosphere. Firstly, zinc $(\mathrm{Zn})$ reacts with oxygen $(\mathrm{O})$ to form $\mathrm{ZnO}$, which will further transform into $\mathrm{Zn}(\mathrm{OH})_{2}$ under a certain humidity. Then, $\mathrm{ZnCO}_{3}$ will be obtained after the reaction between $\mathrm{CO}_{2}$ and $\mathrm{Zn}(\mathrm{OH})_{2}$ and protect the substrate from further corrosion, which is consistent with the electrochemical test. The detailed reaction equations are listed as below:

$$
\begin{aligned}
& 2 \mathrm{Zn}+\mathrm{O}_{2} \rightarrow 2 \mathrm{ZnO} \\
& \mathrm{ZnO}+\mathrm{CO}_{2} \rightarrow \mathrm{ZnCO}_{3} \\
& \mathrm{Zn}(\mathrm{OH})_{2}+\mathrm{CO}_{2} \rightarrow \mathrm{ZnCO}_{3}+\mathrm{H}_{2} \mathrm{O} \\
& 3 \mathrm{Zn}(\mathrm{OH})_{2}+2 \mathrm{ZnCO}_{3} \rightarrow \mathrm{Zn}_{5}\left(\mathrm{CO}_{3}\right)_{2}(\mathrm{OH})_{6} \downarrow
\end{aligned}
$$




\section{Conclusion}

1)The main corrosive products are $\mathrm{Zn}(\mathrm{OH})_{2}, \mathrm{ZnCO}_{3}$ and $\mathrm{Zn}_{5}\left(\mathrm{CO}_{3}\right)_{2}(\mathrm{OH})_{6}$ for galvanized steel in transformer substation;

2)With the increase of exposure time, the corrosive current density increase first and then decrease, resulting from the corrosive products that increase the Rct;

3)After 180 days exposure, the corrosive rate becomes to be stable and the corrosive current density reaches to $0.01 \mathrm{uA} \cdot \mathrm{cm}^{-2}$;

4)The galvanized steels in these four places present different corrosive rate: Industrial area $>$ densely populated area $>$ rural area $>$ chemical industry area, which are mainly affected by $\mathrm{pH}$ value and the amounts of precipitation.

\section{Reference}

[1] X. F.Cao, G. Y.Yang, M. L.Song. Scientific Decision Making,11(2011):76-93.(in Chinese)

[2] Y. Zhou, D. R.Yang. Metallic Functional Materials, 19(2012):13-15.(in Chinese)

[3] X. J.Yuan, J. X.Zhang, X. W.Ji. Corrosion Science and Protection Technology, 25(2013):13-18.(in Chinese)

[4] Z. L.Me, Z. Y.Chen. Electric Power Construction,25(2004):22-36.(in Chinese)

[5] Y. W.Liu, Z. Y.Wang, J.Wang. Journal of Chinese Society for Corrosion and Protection,34(2014):426-432.(in Chinese)

[6] Z. C.Liu, W.Su, S. M.Lu. Guangdong Electric Power,29(2016):104-108.(in Chinese)

[7] S.Liu, H. Y.Sun, H. J.Fan, Materials Protection,45(2012):42-45.(in Chinese)

[8] D. Persson, A. Mikhailov, D. Thierry. Materials and Corrosion,58(2007):452-462.

[9] R. Lindstrom, J E. Svensson, L G. Johansson. Journal of The Electrochemical Society,147(2000):1751-1757.

[10] Y. Y.Chen, S. C.Chung, H. C.Shih. Corrosion science,48(2006):3547-3564. 